\title{
Comparative efficacy of two bio-insecticides in the fight against Helicoverpa armigera (Hubner, 1808) (Lepidoptera: Noctuidae) pest of crops
}

\author{
Ibrahima BA ${ }^{1,2 *}$, Awa NDIAYE ${ }^{2}$, Diouwéria DICKO ${ }^{1,2}$, Mariama FAYE ${ }^{1,2}$ and \\ Mbacké SEMBENE ${ }^{1}$
}

\begin{abstract}
${ }^{1}$ Équipe Génétique et Gestion des Populations (GENGESPOP), Département de Biologie Animale, Faculté des Sciences et Techniques (FST), Université Cheikh Anta Diop (UCAD), B.P 5005, Dakar, Sénégal.

${ }^{2}$ Centre pour le Développement de l'Horticulture (CDH), Institut Sénégalais de Recherches Agricoles (ISRA), Routes des Hydrocarbures, Bel Air, B.P 3120, Dakar, Sénégal.

*Corresponding author, E-mail: ibrahima82.ba@ucad.edu.sn; Tel: +22177 7211763
\end{abstract}

\begin{tabular}{lll}
\hline Received: $30-04-2021$ & Accepted: 02-10-2021 & Published: 30-10-2021 \\
\hline
\end{tabular}

\begin{abstract}
Among the tomato pests, Helicoverpa armigera causes significant damage to the crop. Chemical control is the most commonly used method against this pest and is becoming less and less effective. In order to find out an alternative, a formulation of Helicoverpa armigera nucleopolyhdrovirus (HearNPV) of $0.15 \%$ was compared to a $2 \%$ neem extract product in the laboratory to assess its potential role as a bio-insecticide on the pest. The formulations were tested on stage 2 (L2) larvae up to stage 5 (L5). Results showed 100\% mortality with HearNPV formulation compared to $71.48 \%$ with neem formulation with a highly significant difference (p-0.0001) 6 days after treatment in L2/L3 larvae and $87.92 \%$ versus $70.74 \% 15$ days after treatment in L4/L5 larvae. An average lethal time (LT50) that varies from treatment to treatment has been observed in L4/L5. This TL50 is reduced in L2/L3 and is shorter with neem. These results show that HearNPV formulation appears to be more effective than neem formulation with faster action on young larvae.
\end{abstract}

(C) 2021 International Formulae Group. All rights reserved.

Keywords: Nucleopolyhedrovirus, neem, lethal time, damage, tomato pests.

\section{INTRODUCTION}

The tomato moth or the African capsule worm, Helicoverpa armigera (Heliothis armigera) (Hunner, 1808) (Lepidoptera, Noctuidae), is an indigenous species considered a major constraint on the production of food, fiber and horticultural plants in Africa. Its perception as a particularly severe pest stems from its polyphagia, high fertility and short generation time, high mobility (Feng et al., 2009; Lu and Baker, 2013), its preference for the harvestable fruiting parts of its host plant and its ability to develop resistance to chemical insecticides (Achaleke and Brévault, 2009). The severity of the attack on $H$. armigera varies not only between cultures and regions, but also on a temporal scale. In addition, because of its dispersive and migratory attributes, the incidence of $H$. armigera is unpredictable. $H$. armigera is reported to cause serious damage, particularly on cotton, tomato and maize (Kpindou et al., 2012). On tomatoes, they can 
reduce yield by up to $70 \%$ due to fruit heaviness (Abbas et al., 2015). In Senegal, crop losses due to $H$. armigera on tomatoes are in the range of $60-80 \%$ and population peaks are observed from January to the end of March (PAN/IPEN, 2008).

In sub-Saharan Africa, chemical control is intensely practiced and becomes less and less effective due to the emergence of insecticide resistance genes (pyrethroids) in this moth (Brévault et al., 2008). In addition, there are other adverse effects, such as the emergence of new pests, environmental pollution and the deterioration of human and animal health. Faced with these drawbacks, hopes have turned to other more ecological alternatives such as biological control, in particular the use of bioinsecticides.

The purpose of this study was to contribute to the control of the pest $H$. armigera. Specifically, we evaluated the the bioinsecticidal potential of $H$. armigera nucleopolyedrovirus (HearNPV) and Neem on the larvae Helicoverpa armigera of stage L2 to L5.

\section{MATERIALS AND METHODS}

\section{Larvae of Helicoverpa armigera}

The $H$. armigera larvae used come from the tomato fields of the Centre for the Development of Horticulture (CDH) Camberene and Sangalkham experimental stations. Mass rearing of Helicoverpa armigera on artificial nutrient medium has been set up at the entomology laboratory of $\mathrm{CDH}$. The identification of the larvae was based on the descriptions of Toguebaye and Couilloud (1982).

\section{Helicoverpa armigera nucleopolyhedrovirus bio-insecticide (HearNPV)}

The product to be tested is an insecticide based on $H$. armigera nucleopolyhedrovirus (HearNPV). It is a commercial formulation of Kenyan origin. The active substance is Helicoverpa armigera nucleopolyhedrovirus, belonging to the baculovirus family, with a concentration of $0.15 \%$. The effectiveness of HearNPV was compared to that of a biologic product of $2 \%$ neem extract (azadirachtin).

\section{Reference biological product (neem)}

Fully biodegradable, emulsifiable concentrate product $(0.03 \%$ azadirachtin $)$, neem is a natural fungicide and insect repellent made from its seeds. It is recommended for preventive control of plant diseases and insect infestations during cultivation or post-harvest. The 2\% dose was applied to the L4 / L5 and L2 / L3 larvae of $H$. armigera during treatment.

\section{Tomato leaves}

The leaves come from the greenhouse and tomato fields of the Centre for Horticulture Development (CDH) which have not undergone any insecticide treatment.

\section{Preparation of rearing medium}

To prepare the artificial nutrient medium, $17.5 \mathrm{~g}$ of agar was poured into a liter of distilled water first. The mixture is brought to a boil and stirred well to prevent the formation of lumps and then cool to a temperature of $60^{\circ} \mathrm{C}$. This temperature allows us to obtain a gel which is a fluid. Secondly, a liter of distilled water was poured with $20 \mathrm{~g}$ ascorbic acid, $175 \mathrm{~g}$ corn flour, 43.75 wheat germ, 43.75 brewer's yeast and 1 sachet of 250 $\mathrm{mg}$ erythromycin. The mixture thus made is added to the agar mixture obtained beforehand. The whole is stirred vigorously until homogenized. Then the mixture is sterilized in a water bath at $97^{\circ} \mathrm{C}$ for one hour. The nutrient medium thus prepared is poured into small plastic jars and stored in a refrigerator at $4{ }^{\circ} \mathrm{C}$ until use. The breeding method used was developed by Giret and Couilloud (1987).

\section{Experimental device}

For the assessment of the sensitivity of the $H$. armigera caterpillars to $H$. armigera nucleopolyhedrovirus bioinsecticide (HearNPV), the "soaking" method was used.

The experimental unit is a batch of 10 Petri dishes containing 10 larvae of $H$. armigera. Each test includes the following treatment modalities:it is a batch of 10 Petri dishes containing $10 \mathrm{H}$. armigera larvae. Each test includes the following treatment modalities: 
* Three batches corresponding to larvae subjected to tomato leaves soaked in distilled water (untreated) ;

* Three batches corresponding to the larvae subjected to the reference product (neem);

* Three batches corresponding to the larvae subjected to the bio-insecticide tested.

For each product its reference dose was used and the test was repeated 3 times.

\section{Application of products}

It consisted in feeding the caterpillars with tomato leaves previously soaked in the bio-insecticidal solution of concentration 0.39 $\mathrm{ml}$ for $250 \mathrm{ml}$ of water for the HearNPV and 5 $\mathrm{ml}$ for $250 \mathrm{ml}$ of water for the neem. The solutions are prepared on the same day of the test in emulsion form. The young, green and fresh leaves are harvested on the day of the test from tomato plants which have not previously undergone any insecticide treatment. Once harvested, the leaves are soaked one by one in the solutions for five minutes with gentle agitation, then dried flat on driers for about one hour at $25^{\circ} \mathrm{C}$. They are then placed in Petri dishes containing agarose gel to delay the drying of these. The caterpillars are distributed one by one using a soft forceps in the 10 Petri dishes (containing tomato leaves) constituting the treatments. The control batch consists of leaves soaked in distilled water.

\section{Observation of mortalities}

Observations consisted of counting larval mortality at 3 days, 6 days, 9 days, 12 days and 15 days for the L4 / L5 stages and at 24 hours, 48 hours, 72 hours, 96 hours, 120 hours and 144 hours for L2 / L3 stages. The test is repeated if the percentage of mortality in the control is greater than or equal to $10 \%$.

\section{Statistical analysis}

The percentages of mortality are calculated and corrected relative to the percentages of mortality of the corresponding control using the Abbott formula (Abbott, 1925):
Corrected mortality $(\%)=($ Mortality in the treated group - mortality in the control group) / (100 - mortality in the control group) * 100.

The data collected is entered using a mock-up with the EXCEL spreadsheet. Statistical analyzes are performed with the XLSAT version 2018 software. A normality test was performed with the Shapiro-wilks test. The larval mortality variable L4 / L5 did not follow a normal distribution law therefore the Kruskal wallis and Wilcoxon Manwitney test was used. L2 / L3 larval mortality data were subjected to analysis of variance (ANOVA), means ( \pm standard deviation) are compared using Newman-Keuls multiple comparison tests.

The correlation test allowed us to determine the TL50. P-value values below 0.05 were considered significant.

\section{RESULTS}

\section{Effect of HearNPV and neem oil on $\boldsymbol{H}$.} armigera larvae.

HearNPV and neem had significant effects on $H$. armigera larvae. In $H$. armigera larvae treated with HearNP, there is transparency and stretching of their bodies. On the other hand, moth larvae treated with neem lose their appetite and tend to avoid contact with the leaves. There is also a blackening and shrinking of their bodies.

\section{Effect of HearNPV and neem on L2 / L3 stage larvae}

In stage L2/L3 larvae, only the percentage of neem mortality is significant 24 hours after treatment. For 48 hours, 72 hours, 96 hours and 120 hours after treatment, no significant difference was found between the percentage of death due to HearNPV and that due to neem. On the other hand, it was significantly higher for HearNPV than neem at 144 hours after treatment with a P-value < 0.0001 . There was no significant difference between the percentage of natural mortality (untreated control) and HearNPV 24 hours after treatment, but also between the control, neem and HearNPV 48 hours and 72 hours after 
treatment. The difference is highly significant between the percentage of control mortality and the percentages of mortality due to HearNPV and neem 96 hours, 120 hours, and 144 hours after treatment (Table 1).

\section{Effect of HearNPV and neem on L4 / L5 stage larvae}

Statistical analysis of the percentages of mortality recorded with HearNPV and neem showed no significant difference between the percentage of natural mortality (distilled water control) and the treatments 3 days, 6 days, 9 days and 12 days after treatment. The structuring of the means shows that the HearNPV and neem treatments were not significantly different from one another but were significantly different from the absolute control at the 5\% level on the 15th day after treatment (Table 2).

\section{Lethal time 50 (TL50)}

The lethal times at which $50 \%$ of $H$. armigera larvae died are obtained from the time regression rights based on corrected mortality percentages of HearNPV and neem-treated larvae. The calculation of lethal times at which $50 \%$ of the larvae died (TL50) tells us about the importance of the effect of treatment over time. The TL50 values for each treatment are drawn directly from the regression rights. Indeed, the lethal times calculated, vary from one treatment to another.

\section{TL50 in L2 / L3 larvae}

Compared to the regression right the lowest time: 83 hours or 3.46 days is obtained with the HearNPV, while the highest time: 101 hours or 4.21 days is recorded with the neem (Table 3).

\section{TL50 in L4 / L5 larvae}

The results on HearNPV formulation toxicity and neem oil in terms of lethal time (TL50) (Table 4) revealed that HearNPV recorded a relatively shorter lethal time of 10 days 17 hours compared to neem oil, which recorded a 12-day 2-hour TL50.

Table 1: Mean percentage of mortality in L2 / L3 larvae of $H$. armigera after treatment with Hear NPV and neem.

\begin{tabular}{lcccccc}
\hline \multicolumn{1}{c}{$\begin{array}{c}\text { Hours } \\
\text { Treatments }\end{array}$} & 24 hours & $\mathbf{4 8}$ hours & $\mathbf{7 2}$ hours & $\mathbf{9 6}$ hours & $\mathbf{1 2 0}$ hours & $\mathbf{1 4 4}$ hours \\
\hline HearNPV & $0,000 \mathrm{~b}$ & $23,333 \mathrm{a}$ & $35,553 \mathrm{a}$ & $60,367 \mathrm{a}$ & $85,187 \mathrm{a}$ & $100,000 \mathrm{a}$ \\
& & & & & & \\
\hline Neem & $23,333 \mathrm{a}$ & $27,777 \mathrm{a}$ & $28,147 \mathrm{a}$ & $45,923 \mathrm{a}$ & $60,370 \mathrm{a}$ & $71,483 \mathrm{~b}$ \\
& & & & & & \\
\hline Intreated control & $0,000 \mathrm{~b}$ & $3,333 \mathrm{a}$ & $6,667 \mathrm{a}$ & $6,667 \mathrm{~b}$ & $6,667 \mathrm{~b}$ & $6,667 \mathrm{c}$ \\
& & & & & & \\
\hline Pr > F(Modèle) & $0,004^{*}$ & 0,459 & 0,283 & $0,045^{*}$ & $0,008^{*}$ & $<0,0001^{*}$
\end{tabular}

*P-value Significant

NB: in this table, the means assigned the same alphabetical letter are not significantly different according to the Newman Keuls test $(\mathrm{P}<0.05)$. 
Table 2: Mean percentage mortality of L4 / L5 larvae of Helicoverpa armigera for the different treatments.

\begin{tabular}{|c|c|c|c|c|c|}
\hline Treatments $^{\text {Days }}$ & 3 DAT & 6 DAT & 9 DAT & 12 DAT & 15 DAT \\
\hline HearNPV & $0,000 \mathrm{a}$ & $13,333 \mathrm{a}$ & $34,813 \mathrm{a}$ & $55,183 \mathrm{a}$ & $85,927 \mathrm{a}$ \\
\hline Neem & $6,667 \mathrm{a}$ & $16,667 \mathrm{a}$ & $33,333 \mathrm{a}$ & $43,333 \mathrm{a}$ & $70,740 \mathrm{a}$ \\
\hline Intreated control & $0,000 \mathrm{a}$ & $0,000 \mathrm{a}$ & $3,333 \mathrm{a}$ & $3,333 \mathrm{a}$ & $3,333 \mathrm{~b}$ \\
\hline Pr > F(Modèle) & 0,500 & 0,536 & 0,493 & 0,321 & 0,070 \\
\hline
\end{tabular}

Meaning of abbreviations: DAT $=$ day after treatment

$\mathrm{NB}$ : in this table, the means assigned the same alphabetical letter are not significantly different according to the Newman Keuls test $(\mathrm{P}<0.05)$.

Table 3: Equations of regression lines, regression coefficients and TL50 values for L2 / L3 larvae of Helicoverpa armigera.

\section{L2 / L3 larvae}

TL50

$\begin{array}{lll}\text { Treatments } & \begin{array}{l}\text { Regression lines }(\mathrm{Y}) \text { and } \\ \text { regression coefficients }(\mathrm{R})\end{array} & \text { Value }\end{array}$

\begin{tabular}{lll}
\hline HearNPV & $\mathrm{Y}=0.846 \mathrm{x}-20.298$ & 3 days 11 hours \\
& $\mathrm{R}^{2}=0.993$ & \\
\hline Neem & $\mathrm{Y}=0.424 \mathrm{x}+7.208$ & 4 days 5 hours \\
& $\mathrm{R}^{2}=0.925$ &
\end{tabular}

Table 4: Equations of the regression lines, regression coefficients and the TL50 values for L4/L5 larvae of Helicoverpa armigera according to the treatments.

\begin{tabular}{lll}
\hline L4 / L5 larvae & & TL50 \\
\hline Treatments & $\begin{array}{l}\text { Regression lines (Y) and } \\
\text { regression coefficients }(\mathrm{R})\end{array}$ & Value \\
\hline HearNPV & $\mathrm{Y}=7.123 \mathrm{x}-26.26$ & 10 days and 17 hours \\
& $\mathrm{R}^{2}=0.981$ & \\
\hline Neem & $\mathrm{Y}=5.16 \mathrm{x}-12.295$ & 12 days and 2 hours \\
& $\mathrm{R}^{2}=0.965$ &
\end{tabular}




\section{DISCUSSION}

The long-term use of synthetic insecticides accompanied by serious health and environmental problems (Nathan and Kalaivani, 2006) but also Insect resistance to synthetic insecticides (Ahmad et al., 2003; 2007) and development of awareness of their detrimental effects has prompted the introduction of integrated pest management programs (Nathan and Kalaivani, 2006) for the control of these pests. It is in this context that a laboratory study was carried out with the aim of testing the biological effectiveness of a formulation based on Helicoverpa armigera Nucleopolyhedrovirus (HearNPV). Statistical analyzes of the results of this study revealed that the formulations of HearNPV and neem had a toxic effect on the larvae of Helicoverpa armigera. The effectiveness of these formulations varies according to the stages of larval development of the insect. This may be justified by a difference in vulnerability in the larvae of $H$. armigera. These results agree with those of Zhang et al. (2015) who reported that HaSNPV showed a high virulence and pathogenicity to larvae of $4^{\text {th }}$ and $5^{\text {th }}$ stage of H. armigera.

Over a short period of time, HearNPV application was significantly ineffective on $H$. armigera larvae in contrast to neem extract formulation which caused higher larval mortality. It is well known that a baculovirus infection takes several days to kill the host, so higher mortality with neem oil was expected compared to HearNPV six days after treatment in L4/L5 larvae and two days after treatment in L2/L3 larvae.

However, HearNPV appears to be more effective than neem over time. And this could be justified by the fact that nuclear polyedrosis viruses move from cell to cell after ingestion causing chronic disease and the resulting infected cells disintegrate which ultimately leads to the death of the insect. While, neem is an anti-appetant, an insect growth regulator (Ramya and Jayakumararaj, 2009).

In fact, in L4/L5 larvae, the mortality rate was $85.92 \%$ with HearNPV and $70.74 \%$ with neem with a non-significant difference $(\mathrm{p}$
-0.070) 15 days after treatment. On the other hand, in L2/L3, there was $100 \%$ mortality with HearNPV compared to $71.48 \%$ with neem with a highly significant difference (p -0.0001) 144 hours or 6 days after treatment. These results show that young $H$. armigera larvae are more susceptible to HearNPV than advanced larvae. This could be correlated with resistance in some L4/L5 larvae and corroborates the work of Koppenhifer and Kaya (2000) who had noted a decline in the susceptibility of $H$. virescens to NPV after the second stage. Especially since Pourmirza (2000), Kumar et al. (2008) and Zhang et al. (2015) supported the notion of the sensitivity of early-stage larvae to advanced larvae. The reason for this behavior is not yet properly explored, except that Nathan et al. (2005), who studied the effects of azadirachtin (AZA) and NPV on enzyme activity of the middle intestine in S. litura had noted that enzyme activities of the intestine were decreased by AZA and NPV individually and in combination. But there is still room for further research on the biochemical, molecular and histopathological studies of the middle intestine needed to understand the mechanism of decreased sensitivity of aging larvae.

Knowing how long it takes to kill target insects is crucial information for good pest management. The infectious dosage of a virus is not the only measure of its virulence because the rate of destruction is also important. In this study, HearNPV killed $50 \%$ of $H$. armigera larvae faster than neem oil. The average lethal time (TL50) for L4/L5 larvae treated with HearNPV was 1 day 9 hours shorter than the TL50 of those treated with neem oil and it is reduced to 18 hours in L2/L3 larvae. TL50 was longer in L4/L5 larvae than in L2/L3 larvae. The difference in TL50 between L2/L3 and L4/L5 larvae could be explained by resistance acquisition as the larvae age progresses. However, the results of this study are consistent with the longest lethal times reported in the literature. Ogembo et al. (2005) studying the pathogenicity of two isolates of nucleopolyedrovirus infecting Helicoverpa armigera achieved approximately the same results with TL50s of 2.8 to 11.9 days and 2.8 
to 6.8 days, suggesting a slight increase in resistance within infected larvae as their development. Working on another insect, Masetti et al. (2008), mention during treatment of Spodoptera littoralis with SINPV a 7.32 days TL50 for second stage larvae.

Although this assumption should be verified by field studies, it is likely that an average lethal time of more than seven days is too long to be very useful in preventing economic losses on most crops. Inefficiency in achieving rapid reduction in pest populations is one of the main drawbacks of baculoviruses and one of the reasons why farmers are often opposed to the use of these control agents (Toprak et al., 2007).

The nuclear polyedrosis virus must be ingested by the larvae in order to be effective, therefore, good target coverage is essential. In addition, it is noted that a living organism loses its power when exposed to sunlight, especially the ultraviolet component. Therefore, repeated applications and much higher doses would be required for field control of $H$. armigera throughout a culture cycle. For maximum efficacy, it is essential to apply the right amount of virus to achieve an acceptable reduction of the larval population.

HearNPV could be used as an alternative in the fight against $H$. armigera in the same way as most viral formulations (Lavina et al., 2001).

\section{Conclusion}

This work was carried out with the aim to determine insecticidal effect of Helicoverpa armigera Nucleopolyhdrovirus on the larvae of $H$. armigera. The results show that the effectiveness of HearNPV can match or even outperform neem oil on $H$. armigera larvae depending on the stage of development. However, this effectiveness decreases as the age of the larvae progresses. Mortality is $100 \%$ with an LT50 of 3.46 with HearNPV formulation while it is $71.48 \%$ with a 4.21 -day LT50 with neem with a highly significant difference (p-0.0001) to six (6) days after treatment in L2/L3 larvae. In L4/L5 larvae, the mortality rate was $87.92 \%$ with an average lethal time (LT50) of 10.7 days with HearNPV versus $70.74 \%$ with a 12 -day LT50 with neem at fifteen (15) days after treatment.

\section{COMPETING INTERESTS}

The authors declare that they have no competing interests.

\section{AUTHORS' CONTRIBUTIONS}

IB contributed to the definition of experimental protocols, field data collection, statistical data analysis and article writing. AN contributed to the coordination of activities, the definition of experimental protocols and manuscript correction. DD contributed to the breeding of insects in the laboratory. MF contributed to the manuscript correction and MS contributed to the coordination of activities.

\section{ACKNOWLEDGMENTS}

We thank the Centre for the Development of Horticulture of the Senegalese Institute of Agricultural Research which allowed us to carry out this work and the Cheikh Anta Diop University in particular GENGESPOP research team for the supervision

\section{REFERENCES}

Abbas G, Hassan N, Farhan M, Haq I, Karar H. 2015. Effect of selected insecticides on Helicoverpa armigera Hubner (Lepidoptera: Noctuidae) on tomato (Lycopersicon esculentum Miller) and their successful management. Advances in Entomology, $\quad 3(1): \quad 16-23$. DOI: $10.4236 / \mathrm{ae} .2015 .31003$

Abbott WS. 1925. A method of computing the effectiveness of an insecticide. Journal of Economic Entomology, 18(2): 265-267. DOI: https://doi.org/10.1093/jee/18.2.265a

Achaleke J, Martin T, Ghogomu RT, Vaissayre M, Brévault T. 2009. Esterase mediated resistance to pyrethroids in field populations of Helicoverpa armigera (Lepidoptera: Noctuidae) from Central Africa. Pest Management Science, 
65(10): $1147-1154 . \quad$ DOI: https://doi.org/10.1002/ps.1807

Ahmad M, Arif MI, Ahmad Z. 2003. Susceptibility of Helicoverpa armigera (Lepidoptera: Noctuidae) to new chemistries in Pakistan. Crop Protection, 22(3): 539-544. DOI: https://doi.org/10.1016/S02612194(02)00219-3

Ahmad M, Arif MI, Ahmad M. 2007. Occurrence of insecticide resistance in field populations of Spodoptera litura (Lepidoptera: Noctuidae) in Pakistan. Crop Protection, 26(6): 809-817. DOI: https://doi.org/10.1016/j.cropro.200 6.07 .006

Brévault T, Achaleke J, Sougnabé SP, Vaissayre M. 2008. Tracking pyrethroid resistance in the polyphagous bollworm, Helicoverpa armigera (Lepidoptera: Noctuidae), in the shifting landscape of a cotton-growing area. Bulletin of Entomological Research, 98(6): $565-573 . \quad$ DOI: https://doi.org/10.1017/S0007485308005 877

Feng H, Wu X, Wu B, Wu K. 2009. Seasonal Migration of Helicoverpa armigera (Lepidoptera: Noctuidae) over the bohai sea. Journal of Economic Entomology, 102(1): 95-104. DOI: https://doi.org/10.1603/029.102.0114

Giret M, Couilloud R. 1987. Production d'Heliothis armigera (Hübner) (Lepidoptera, Noctuidae) : technique d'élevage en groupe des chenilles. Coton et Fibres Tropicales, 42(3): 211-216.

Koppenhöfer AM, Kaya HK. 2000. Interactions of a Nucleopolyhedrovirus with Azadirachtin and Imidacloprid. Journal of Invertebrate Pathology, 75(1): 84-86. DOI:

https://doi.org/10.1006/jipa.1999.4889

Kpindou OKD, Djegui DA, Glitho IA, Tamò M. 2012. Réponse des stades larvaires de Helicoverpa armigera (Hübner) (Lepidoptera : Noctuidae) à l'application de champignons entomopathogènes
Metarhizium anisopliae et Beauveria bassiana. Biotechnology, Agronomy, Society and Environment, 16(3): 283-293.

Kumar SN, Murugan K, Zhang W. 2008. Additive Interaction of Helicoverpa Armigera Nucleopolyhedrovirus and Azadirachtin. Biological Control, 53(6): 869-880.

https://www.researchgate.net/deref/http\% $3 \mathrm{~A} \% 2 \mathrm{~F} \% 2 \mathrm{Fdx}$.doi.org\%2F10.1007\%2Fs 10526-007-9115-Z

Laviña BA, Padua LE, Wu FQ, Shirata N, Ikeda M, Kobayashi M. 2001. Biological Characterization of a Nucleopolyhedrovirus of Spodoptera litura (Lepidoptera: Noctuidae) Isolated from the Philippines. Biological Control, 20(1): 39-47.

DOI:

https://doi.org/10.1006/bcon.2000.0877

Lu ZZ, Baker G. 2013. Spatial and temporal dynamics of Helicoverpa armigera (Lepidoptera, Noctuidae) in contrasting agricultural landscapes in northwestern China. International Journal of Pest Management, 59 (1): 25-34. DOI: https://doi.org/10.1080/09670874.2012.7 42936

Masetti A, Valentino De Luigi V, Burgio G. 2008. Effects of nucleopolyhedrovirus based product on Spodoptera littoralis. Bulletin of Insectology, 61(2): 299-302. DOI:

http://www.bulletinofinsectology.org/

Nathan SS, Kalaivani K. 2006. Combined Effects of Azadirachtin and Nucleopolyhedrovirus (SpltNPV) on Spodoptera Litura Fabricius (Lepidoptera: Noctuidae) Larvae. Biological Control, 39(1) : 96-104. DOI : https://doi.org/10.1016/j.biocontrol.2006. 06.013

Nathan SS, Kalaivani K. 2005. Efficacy of nucleopolyhedrovirus and azadirachtin on Spodoptera litura Fabricius (Lepidoptera: Noctuidae). Biological Control, 34(1): 93-98.

DOI: https://doi.org/10.1016/j.biocontrol.2005. 03.001 
Ogembo JG, Kunjeku EC, Sithanantham S. 2005. A preliminary study on the pathogenicity of two isolates of nucleopolyhedroviruses infecting African bollworm, Helicoverpa armigera (Lepidoptera: Noctuidae). International Journal of Tropical Insect Science, 25(3): 218-222.

DOI: https://doi.org/10.1079/IJT200569

PAN/IPEN. 2008. Interdiction de l'endosulfan dans les pays du sahel en Afrique de l'ouest,

$55 \mathrm{p}$. www.ipen.org/ipenweb/documents/.../rap $\%$ 20endosulfan_french.pdf

Pourmirza AA. 2000. Relationship between Nuclear Polyhedrosis Virus Susceptibility and Larval Weight in Heliothis armigera. Journal of Agricultural Science and Technology, 2(4): 291-298. www.sid.ir

Ramya S, Jayakumararaj R. 2009. Antifeedant Activity of Selected Ethno-Botanicals Used by Tribals of Vattal Hills on Helicoverpa armigera (Hübner). Journal of Pharmacy Research, 2(8): 1414-1418.
Toguebaye BS, Couilloud R. 1982. Etude descriptive de l'œuf et des stades larvaires d'Heliothis armigera (Hübner 1908) (Lepidoptera Noctuidae) en microscopie électronique à balayage. Coton et Fibres Tropicales, 37: 197-209.

Toprak U, Gürkan MO, Bayram S. 2007. Impact of a Turkish isolate and a plaque purified variant of SpliNPV-B on larval stage development of Spodoptera littoralis (Lepidoptera: Noctuidae) Boisd. Pest Management Science, 63(6): 564568.

DOI: https://doi.org/10.1002/ps.1370

Zhang S, Wu F, Li Z, Lu Z, Zhang X, Zhang Q, Liu X. 2015. Effects of Nucleopolyhedrovirus Infection on the Development of Helicoverpa Armigera (Lepidoptera: Noctuidae) and Expression of Its 20-Hydroxyecdysone and Juvenile Hormone Related Genes. Florida Entomologist, 98(2): 682-89. DOI: https://doi.org/10.1653/024.098.0243. 